\title{
Improving fiber quality by reducing seed damage in the gin machine
}

\author{
Elmira Mukhametshina ${ }^{1 *}$, Rustam Muradov ${ }^{1}$, Ilkhom Abbazov ${ }^{1}$, and Alisher Usmankulov ${ }^{1}$ \\ ${ }^{1}$ Jizzakh Polytechnic Institute, 130100 Jizzakh, Uzbekistan
}

\begin{abstract}
The article focuses on the prevention of seed damage in a gin machine and conducts research on what parameters of the gin machine affect seed damage. Based on the analysis of scientific research in this area, it was established and studied that the density of the raw material roller and its rotation speed, as well as the release of fibers from the working chamber are factors influencing seed damage. Scientific research on the density of raw materials and the acceleration of turnover have been analyzed. Based on the analysis, the acceleration of the rotation of the raw material roller is based on obtaining optimal results, which is carried out using a rotating disk with piles on the side of the working chamber. It is also scientifically proven that the surface of the gutter must be grooved in order to timely remove the seeds separated from the fiber from the working chamber of the gin. Practical studies have shown that as a result of turning the side of the working chamber of the gin machine, the short fiber index in the fiber content decreased by $1.5 \%$, Str-specific tensile strength 0.4 qs / tex and Ehgelongation elongation improved by $0.2 \%$.
\end{abstract}

\section{Introduction}

Raw cotton is one of the most valuable raw materials, from which up to 350 types of consumer goods and technical purposes are produced. Cotton fiber serves as the main raw material for textile, knitwear and other light industries. A wide variety of fabrics, sewing threads, cotton wool, artificial silk, cord threads used in the automotive industry, filters, drive belts, artificial leather and much more are produced from it. Getting high quality products mainly depends on the storage and processing of raw cotton [1]. The main content of the initial processing of seed cotton is the separation of fiber from the seed, which is a complex technological process consisting of several operations, dozens of passes, ensuring the quality of fiber, seeds and other components [2].

Extensive research is being conducted around the world to improve the technology of the process of separating cotton fiber from seeds, to create new fiber separation machines, as well as new working bodies for existing machines. In this regard, special attention is paid to improving product quality and reducing costs, including the development of a scientific basis for improving the efficiency of the process of separation of cotton fiber, accelerating the widespread introduction of scientific, as well as modern, automated equipment and technologies [3]. At the same time, in the process of separating cotton fiber from seeds, it is important to maintain the original quality of fiber and seed, to create compact technologies that can control the quality of the product, to reduce energy consumption, to create perfect designs of cotton fiber separation equipment.

The main technological machine of cotton ginning factories are gins, intended for separating cotton fiber from seeds and working on processing: long-staple varieties of raw cotton - feller gin, medium-staple varieties of raw cotton - saw gin - 2. In the initial period, the separation of fibers from cotton seeds was done manually; the productivity of one worker per day was about $1 \mathrm{~kg}$ of fiber.

The biggest development was the invention of the saw gin by Eli Whitney, the prototype of modern fiber separators. In Whitney's gin, the main working organ was a wooden drum, with slightly curved wire needles mounted on it, which, when the drum rotated, caught the fiber and separated it from the seed. Whitney's invention was the impetus for the rapid improvement of machines for separating fiber from seed [4]. Further, Hodgin Holmes proposed a saw gin with a fixed seed comb, and I. Perkins introduced a movable seed comb, which made it possible to regulate the degree of exposure of cotton seeds. Eli Whitney followed the Hodgin Holmes principle and made a steel saw blade, which had a diameter of $173 \mathrm{~mm}$, the gap between the stitches was $18.8 \mathrm{~mm}$, and the rotation speed was $200 \mathrm{~min}-1$. The first sawing gins were imported to Central Asia from the USA, but already in 1925 sawing gins began to be produced at the Nevsky

* Corresponding author: elmirasmart308@gmail.com 
Mechanical Shipbuilding Plant. In the same year, works appeared that were the beginning of the study of the ginning process.

\section{Methods}

The condition of the raw material roller formed in the working chamber is mainly caused by the seed damage in the gin machine (Fig. 1).

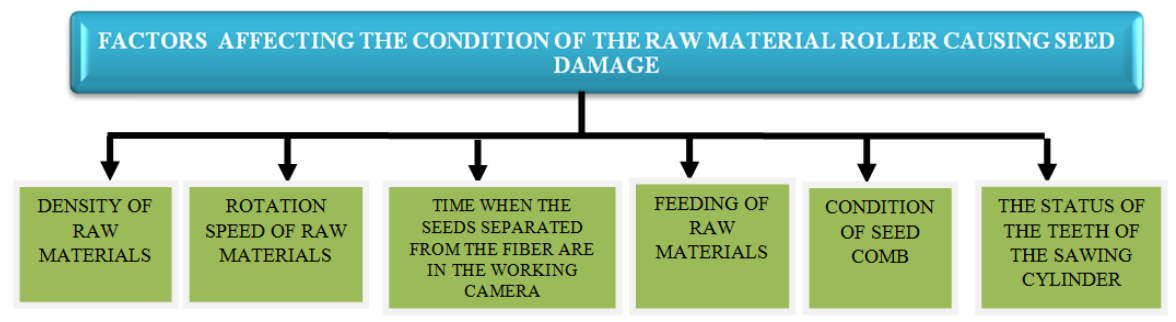

Fig.1. Factors that cause seed damage

Fig. 1 shows the parameters that cause seed damage in a gin machine [5].

Over the years, a number of studies have focused on increasing the effectiveness of gin and reducing seed damage. To solve this, parameters such as the configuration of the working chamber, the position of the seed comb for free release of frantic seeds from the working chamber, the shape of the columns, the geometry of the saw tooth, the speed mode of the saw cylinder, the diameter of the saw cylinder, the distance between saws were studied.

The researchers studied the composition, nature and speed of the raw roller, the separation of seeds from the working chamber, the shape of the working chamber and saw teeth, the cause of defects in the grinding process and the coverage of the saw teeth. found that the plain is not covered with fiber and not all are involved in ginning. Researchers believe that it is necessary to increase the number of revolutions of the saw cylinder to $700 \div 730$ min- 1 , reduce the relative speed of the roller relative to the saw, accelerate the exit of seeds from the center of the chamber, improve the shape of the raw chamber [6].

It is also believed that the main ways to increase the efficiency of sawdust gin, to reduce seed damage, is to increase the fiber content of the raw material roller, quickly remove the cleaned seeds and reduce its density evenly. The widespread use of oversized working chambers in the cotton ginning industry has made it possible to increase the efficiency of ginners to productivity of $10 \mathrm{~kg} / \mathrm{saw}$ hour and above.

According to the researchers, improving the quality of the fiber as a result of the gin working in an expanded chamber is mainly due to reducing the density of the raw material roller, which improves fiber coverage, reduces the friction force of cotton on the cell walls and saves energy [7].

In the work of R. Sulaymanov [8] an algorithm for solving the problem of dynamics and mathematical models of seed movement, which theoretically allows to determine the optimal parameters of the distance between the console columns, columns and inserts in the production of additional seeds. Based on them, the distance between the saws was reduced, and a new method and device for extracting additional seeds was proposed.

In the research of J. Ergashev [9], a hole was made in the bottom of the pipe, which was mounted on the working chamber of the gin machine. When air is pumped into the pipe, the air flow coming out through this hole is directed towards the cylinder. As a result, the amount of fiber adhering to the saw cylinder teeth under the influence of air is increased. The airflow directed towards the saw cylinder accelerates the exit of the seeds separated from the fiber from the working chamber.

The authors analyzed the formation of defects during ginning and cited Table 1 of fiber damage.

Table 1. Fiber damage

\begin{tabular}{|l|c|c|}
\hline \multicolumn{1}{|c|}{ Fibre } & Maturity & Mechanical damage fiber, \% \\
\hline The first raw cotton & 4.8 & 2.0 \\
\hline \multicolumn{2}{|c|}{ After passing the raw material governor } \\
\hline Strained & 4.2 & 25.5 \\
Average & 4.4 & 18.5 \\
Empty & 4.7 & 9.0 \\
\hline
\end{tabular}

Analyzing the work done on the study of mechanical defects of fibers, the following conclusion can be drawn: ehe main shortcoming of the researchers is that the research was conducted on artificially damaged cotton samples, which is far from the real-world damage [10].

V.G.Gulidov found in his work that productivity, seed damage and the speed of the raw roller are largely dependent on the number of saw teeth and tooth height when they are the same. As the number of teeth decreases, the density of the raw roller decreases, but as the number of revolutions of the saw cylinder increases, the productivity increases sharply. 
Another key practical measure is to reduce the density of the raw roller and seed damage by reducing the number of teeth. In this case, the reduction of the saw teeth allows to increase its size.

An analysis of studies conducted so far shows that they do not reveal many aspects of the process of sawdust firing. Extensive research is being conducted around the world to improve the technology of primary processing of cotton, including the process of separation (ginning) of cotton fiber from seeds, ginning and technology.

In this direction, in particular, the scientific basis for improving the efficiency of the process of ginning cotton is being developed, special attention is paid to improving product quality and reducing costs by accelerating the widespread introduction of scientific techniques and technologies in production. At the same time, in the process of separating cotton fiber from seeds, it is important to maintain the original quality of fiber and seeds, to create compact technologies that can reduce product energy consumption, product quality, low-cost and energy-efficient designs of cotton fiber separators.

In search of solutions to the selected scientific and technical tasks in accordance with these objectives, the author set the following main tasks:

- search and development of special optimal constructions of technical means providing experimental inspections of the interaction of saws of fiber separation machines with fiber masses;

- study of the composition of the raw material roller, which is formed in the working chamber in the process of separation of fiber from seeds using sawdust gin;

- selection of the optimal dimensions of the elements of the fiber separation machine, checking their effect on the quality indicators of seed and cotton fiber.

Among the factors it is necessary to take into account the condition of the working surface of the saw, which affects the power consumption during sawing, it is most important that it depends on the friction force generated between the chimney and the raw material chamber.

The power problem of the saw blade is solved by dynamic analysis of the interaction between the working body and the cylinder and the raw material roller.

Examining the scientific work in the field of sawing, it can be seen that the main theoretical and experimental research has been aimed at determining the optimal shape of the working chamber, the parameters of the saw teeth and their coverage, as well as the effect of raw material density on the quality of the product. However, in these studies, little attention was paid to energy consumption during spinning, fiber and seed damage, which did not take into account the actual loads and individual parameters and dynamics of the machines.

The authors studied the quality of the fiber obtained in gin when the density of the raw material roller was low. In the experiments, $108 \mathrm{~F}$ I-grade cotton was harvested by hand, with a moisture content of $7.2 \%$ and pre-ginning contamination of $0.4 \%$. The results of gin work with an elastic element saw of a raw material shaft with a diameter of $150 \mathrm{~mm}$ and a speed of $230 \mathrm{rpm}$ were compared with 3XDD-M gin work indicators. The schematic of the pegs mounted on the side of the jin working chamber is shown in Figure 2, in which the 1st working chamber is mounted on the disk on the side of the 2 nd working chamber and the 3 rd pegs are mounted. A variety of accelerators that were rotated to the side of the working chamber were installed and used.

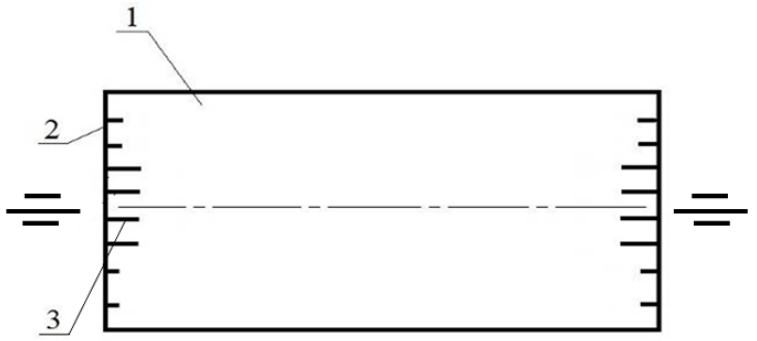

Fig. 2. Schematic of the pegs mounted on the side of the gin working chamber Patent №FAP 00990 working chamber, 2- working chamber side, 3-pegs

Experiments on this device were conducted in 3 different variants. In option 1, the length of the pegs mounted on the side of the gin working chamber is h1-15 mm, h2-10 mm. In option 2, the piles were made with h1-30 mm and h2-15 $\mathrm{mm}$ in length (Fig. 2 and 3). In variant 3, convex blades are mounted on the side of the gin working chamber [11].

\section{Results and Discussions}

As a result of the experiments, the effects of accelerators on the speed of rotation of the raw roller, the output of seeds separated from the fiber from the working chamber, the density of the raw roller and seed damage were studied. In the first experiments, it was found that in the third option, the rotation speed of the raw material roller does not change as much as necessary. Therefore, subsequent studies have studied the effects of pile accelerators $[12,13]$.

It was found that when the rotational speed of the accelerator is $150-250 \mathrm{rpm}$ and the length of the accelerator piles is different, the working efficiency and product quality of the gin machine are different. 


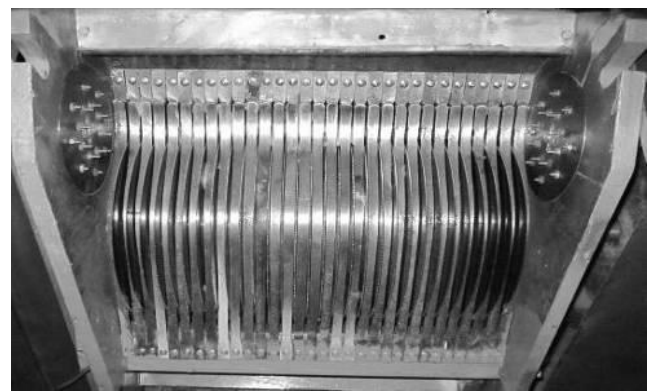

Fig. 3. The appearance of the pegs mounted on the side of the jin working chamber

Also in the initial studies: all the piles were the same size; the pegs in the center are short and the edges are long; variants in which the central pegs were long and the outer pegs were short were examined. When the rotational speed of the accelerators mounted on the side of the working chamber was $150 \mathrm{r} / \mathrm{pm}$, it was found that the rotational speed of the raw roller through the slit of the front apron of the working chamber was in the range of $120 \mathrm{r} / \mathrm{pm} \mathrm{[14].}$

When the rotational speed of the accelerators mounted on the side of the working chamber was $200 \mathrm{r} / \mathrm{pm}$, it was found that the rotation speed of the raw material roller through the slit of the front apron of the working chamber was in the range of $160 \mathrm{r} / \mathrm{pm}$.

When the rotational speed of the accelerators mounted on the side of the working chamber was $240 \mathrm{r} / \mathrm{pm}$, it was found that the rotation speed of the raw material roller through the slit of the front apron of the working chamber was in the range of $180 \mathrm{r} / \mathrm{pm}$.

Based on the results obtained, the following graphs were constructed: Fig. 4 shows the effect of the accelerator on the rotation of the raw roller, from which the accelerator has a positive effect on the speed of the raw roller.

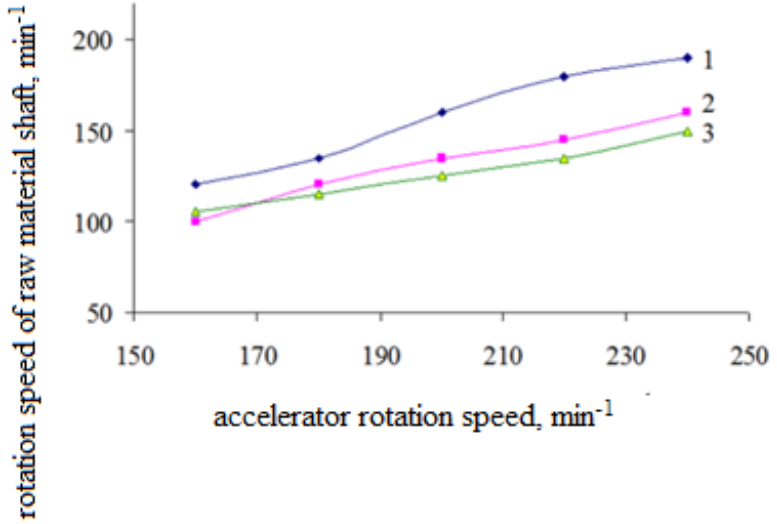

Fig. 4. The effect of the accelerator on the rotation of the raw material shaft

In this case, it was observed that the speed was higher when the piles were the longest, but in this variant, the state of elongation in the cotton fibers around the piles was determined. The required acceleration was not observed in the bubble discs. In the first experiments, variants with the same length of pegs and long pegs at the edges and shorter pegs in the center were examined. At the same time, it was observed that the fibers in the raw material roller, which had entered the zone of impact of the piles, were cracked. Accordingly, for subsequent studies, an option was chosen in which the central piles were long and the outer piles were short. The following 3 options were studied: 1 - center piles $30 \mathrm{~mm}$ and peripheral piles $15 \mathrm{~mm}, 2$ - center piles $15 \mathrm{~mm}$ and peripheral piles $10 \mathrm{~mm}, 3$ - center piles $10 \mathrm{~mm}$ and peripheral piles $5 \mathrm{~mm}$.

Fig. 5 shows the effect of the accelerator on the output of the fibers separated from the fiber from the working chamber, and Fig. 6 shows the effect of the accelerator on the density of the raw material shaft. According to them, long piles increase seed germination and productivity, but the resulting fiber growth leads to an increase in knots in the fiber content and a decrease in quality.

An increase in the accelerator speed also causes a change in the density of the raw material shaft. At the same time, in the variants with relatively sharp, medium and short piles on long piles, the decrease in the density of raw materials is relatively moderate.

It showed that the weight of the raw material roller was reduced by $25-28 \%$ when the speed of the accelerator mounted on the working chamber was $250 \mathrm{r} / \mathrm{pm}$. In conclusion, the accelerator installed in the gin working chamber not only 
increases the productivity of the gin machine, but also improves the fiber quality and reduces the seed damage, and brings significant economic efficiency to the ginnery [15].

The cotton that falls into Jin's working chamber is picked up by saw teeth rotating next to the seed comb and brought to the grate. In the working chamber, the cotton pieces attached to the teeth stick to the other cotton pieces, pulling them as well and forming a raw roller. This roller rotates in the opposite direction to the saw rotation and it provides the saw teeth with cotton fiber continuously.

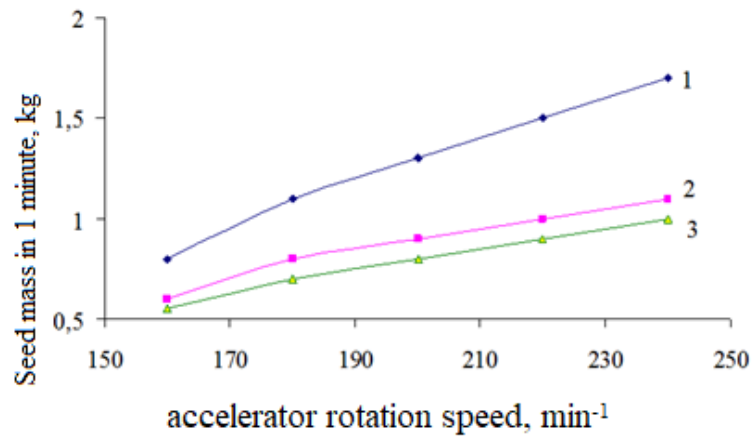

Fig. 5. The effect of the accelerator on the output of the seed separated from the fiber from the working chamber

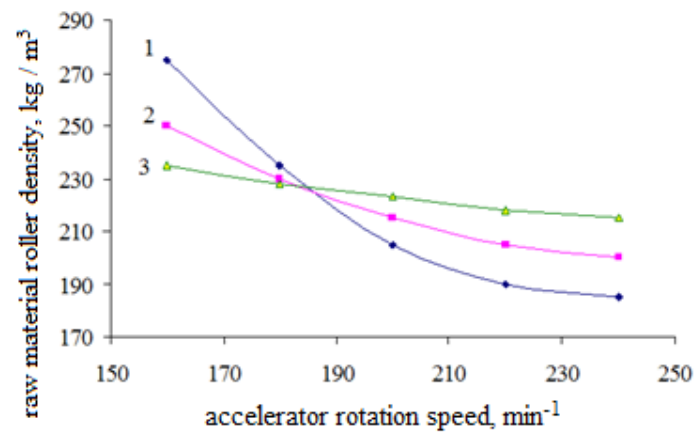

Fig. 6. The effect of the accelerator on the density of the raw material shaft

\section{Conclusions}

Based on research on the gin machine, the parameters that cause seed damage have been identified. The density of the raw material roller, which is the most important of the identified parameters, and its rotation speed, as well as the release of seeds separated from the fiber from the working chamber were studied in detail.

The authors analyzed studies on the density of raw materials and the acceleration of turnover. Based on the analysis, the acceleration of the rotation of the raw material roller is carried out using a rotating disk with pegs mounted on the side of the working chamber. It was also suggested that the surface of the column be grooved so that the seeds separated from the fiber could be removed from the working chamber of the demon in a timely manner.

As a result of turning the side of the working chamber of the gin machine (moisture content of cotton $10.9 \%$, dirt $2.4 \%$, selection variety Namangan-77, industrial grade III class 2 ), the short fiber index decreased by $1.5 \%$, Str. -relative elongation at $0.4 \mathrm{qs} /$ tex and elongation at Ehg-interruption by $0.2 \%$.

\section{References}

1. A. Yu. Ergashev, Primary processing of raw cotton and the impact on the quality of yarn production, Young Scientist 7(66), 193-195 (2014)

2. A. A. Umarov, Study of the issues of creating optimal control systems for cotton ginning equipment, Candidate of Technical Sciences Dissertation, Tashkent (2010)

3. E. T. Muxametshina, A. Jamolov, R. M. Muradov, Study on possibilities of scarring ways to reduce in the cotton cleaning process, IOP Conf. Ser.: Earth Environ. Sci. 614, 012128 (2020)

4. G. I. Miroshnichenko Fundamentals of designing machines for primary processing of cotton, The Teacher, Tashkent (1998)

5. G'. J. Jabborov, T. U. Otametov, A. Hamidov, Technology of primary processing of seed cotton, The Teacher Tashkent (1987) 
6. H. Yu. Ulugmuradov, I. Z. Abbazov, R. M. Muradov, Study on improving the efficiency of cleaning the pile drum, IOP Conf. Ser.: Earth Environ. Sci. 614, 012127 (2020).

7. E. Zikriyoev, Primary processing of cotton, Labor, Tashkent (2002)

8. R. Sulaimanov, Development of a working chamber with improved seed production during saw ginning of raw cotton, Candidate of Technical Sciences Dissertation, Tashkent (2006)

9. Zh. S. Ergashev, Improving the technology of saw ginning in order to increase the quantitative and qualitative indicators, Candidate of Technical Sciences Dissertation, Tashkent (1991)

10. K. J. Djumaniyazov, I. Z. Abbazov, D. E. Kazakova, Change of physical and mechanical indicators of yarn depending on the design of the sampling drum, Journal of Critical Reviews 7(3), 411-415 (2020)

11. A. Sarimsaqov, J. Ergashev, R. Muradov, Study of the condition of the raw material shaft formed in the working chamber of the gin machine, FarPI. Scientific and Technical Journal 2, 34-37 (2012)

12. A. Sarimsakov, R. Muradov, Improving the efficiency of the jin machine by improving its design, FarPI. Scientific and Technical Journal 1, 34-37 (2013)

13. A. Sarimsakov, R. M. Muradov, J. S. Ergashev, S. Muxiddinov, Patent UZ №FAP 00990, Working camera of saw gin. Byul. №2. 27.02.2015.

14. K. Muksin, A. Ilkhom, M. Iqbol, K. Javlon, R. Marguba, Technological breakthrough of cotton cleaning enterprises fiber waste, European Journal of Molecular \& Clinical Medicine 7(2), 508-515 (2020)

15. K. Muksin, A. Ilkhom, K. Javlon, A new technology for dust removal from cotton processing, Int. J. Recent Technology and Engineering 8(3), 583-586 (2019). 